\title{
Evaluation of Perinatal Outcome in Women with Impaired Glucose Homeostasis During Pregnancy
}

\author{
Neha SAHAY ${ }^{1}$, Felice FAIZAL ${ }^{2}$
}

\begin{abstract} by the following criteria:

1. Abnormal GCT ( $\geq 140 \mathrm{mg} / \mathrm{dl})$ with normal OGTT;

2. Normal GCT with only Impaired Fasting Glucose(IFG) in OGTT;

3. Normal GCT with Gestational Glucose Intolerance(GGI);

4. Patients diagnosed as GDM:

a. If fasting is $>126 \mathrm{mg} / \mathrm{dl}$;

b. If $2 \mathrm{hr} \mathrm{OGTT} \geq 140 \mathrm{mg} / \mathrm{dl} \& \leq 199 \mathrm{mg} / \mathrm{dl}$;

c. If value of either GCT or OGTT $\geq 200 \mathrm{mg} / \mathrm{dl}$.
\end{abstract}

Background: Glucose tolerance testing in pregnancy identifies many women with glycaemic responses that exceed normal range but that do not meet the threshold required to diagnose Gestational Diabetes Mellitus. It is controversial whether maternal hyperglycemia less severe than in diabetes is associated with increased risk of adverse pregnancy outcome or not. Materials and methods:_All women were subjected to Glucose Challenge Test(GCT) with 50 gram glucose either at first visit or between 24-28 weeks on the basis of risk profile. High risk cases were screened at first visit and the rest between 24-28 weeks. Patients with a GCT value $\geq 200 \mathrm{mg} / \mathrm{dl}$ were not subjected for GTT and were diagnosed as GDM.Value of GCT <140 mg/dl was taken as normal. Irrespective of GCT result, women were subjected to Oral Glucose Tolerance Test (OGTT) as recommended by WHO with 75 gram glucose using WHO criteria. Study group was identified with 4 categories with abnormal glucose homoeostasis as defined

The control group comprised of women with normal GCT and normal OGTT. In all the above groups, adverse prenatal outcome and maternal outcomes were evaluated by the primary and secondary outcome measures.

Results: There were 10 cases (15.3\%) of hypertensive disorder of pregnancy in the study group (3 cases of gestational hypertension in abnormal GCT, 3 cases of pre eclampsia in each GGI and GDM and 1 antepartum eclampsia in GGI category) and 2 cases in control group (3\%) $(p=0.03)$. There were 2 cases of Fetal Growth Reduction (FGR) and 5 cases of Premature Rupture Of Membranes(PROM) in both study and control group. There was 1 case of cholestasis of pregnancy in study group. Term inductions were 11 and 13 in the study and control group respectively. Within the study group number of cases induced were more in $\mathrm{GGI}(\mathrm{n}=7)$ and $\mathrm{GDM}(\mathrm{n}=4)$ category. There were 14 caesarean sections (21.5\%) and $2(3 \%)$ instrumental deliveries among the study group. However there were 6 caesarean sections (9.2\%) and no instrumental deliveries among control groups. The rate of elective LSCS is more in GDM $(n=5)$ vs other 3 categories and the difference is significant ( $p=0.04)$ The overall number of LSCS ( 14 cases) was significantly higher in GDM.

Conclusion: Cases with abnormal glucose homeostasis of lesser degree than GDM, like only abnormal GCT, IFG and $\mathrm{GGI}$ also were observed to have adverse maternal outcomes than controls, in form of hypertensive disorders of pregnancy, significantly higher LSCS rates, and increased risk of macrosomia. Instead of 2 step procedure, single step screening cum diagnostic test with $75 \mathrm{gm}$ OGTT for diagnosing GDM could be an option to be universally practiced.

Keywords: women, glucose, homeostasis, pregnancy, diabetes.

${ }^{1}$ Armed Forces Medical Services, Government of India

${ }^{2}$ Department of Pathology, Base Hospital, Srinagar, India
Corresponding author:

Felice FAIZAL, A 201, Kailash towers, IGNOU road, New Delhi, 110030, India.

E-mail: flcfzl@gmail.com 


\section{INTRODUCTION}

Gestational diabetes mellitus (GDM), a common medical complication of pregnancy, is defined as "any degree of glucose intolerance with onset or first recognition during pregnancy" ${ }^{1,2}$. Its prevalence is $7 \%$ of all pregnancies according to American Diabetes Association (ADA). The initial criteria for its diagnosis were established more than 40 years ago and, with modifications, continue to be used even to date. ${ }^{3,4}$ Some studies suggest that criteria currently in wide use for the diagnosis of GDM are too restrictive and that lesser degrees of hyperglycemia increase risk of adverse perinatal outcomes ${ }^{5,6}$. There is consensus now that overt diabetes during pregnancy, whether symptomatic or not, is associated with significant risk of adverse perinatal outcome such as large for gestational age (LGA), excess fetal adiposity, and higher rate of cesarean section. GDM is diagnosed on the basis of the glucose level that exceeds specific glycaemia thresholds. Affected women identified in this way are then treated with dietary therapy and /or insulin to achieve targeted glycemic control during pregnancy.

It is important to recognize however that glucose tolerance testing in pregnancy also identifies many women with glycaemic responses that exceed normal range but that do not meet the threshold required to diagnose GDM. It is controversial whether maternal hyperglycemia less severe than in diabetes is associated with increased risk of adverse pregnancy outcome.

In this context, the objectives of this study are designed so as to detect any adverse perinatal event characterizes cohort of women repesenting a broad spectrum of abnormal glucose homeostasis documented during the process of screening for gestational Diabetes Mellitus.

\section{MATERIAL AND METHODS}

Considering the prevalence of abnormal GCT(Glucose challenge test) as 10\% IGT (Impaired glucose tolerance) as $7-10 \%$ and GDM(Gestational diabetes mellitus)as $12-15 \%$ to estimate a difference with an error of $5-7 \%$ a sample size of 250 cases was calculated keeping confidence level as $95 \%$.

Every day, first 7 antenatal women reporting for ANC check-up, before 28 weeks of gestation were recruited for screening.
Pregnant women recruited in study underwent a thorough clinical examination after a detailed clinical history. Relevant points recorded in history were:

- Polyuria, polyphagia, polydipsia;

- Discharge per vaginum, history of recurrent infections;

- Previous poor obstetric history;

- Macrosomia in previous pregnancy;

- Family history of diabetes in first degree relatives;

- Previous history of GDM.

Besides routine general physical examination, systemic examination and obstetric examination, the following parameters were documented:

- Pre pregnancy weight;

- Pre pregnancy BMI;

- Blood pressure measurement $(\mathrm{mm} \mathrm{Hg})$ in right arm sitting position;

- Clinically estimated fetal weight;

- Local discharge per vaginum.

All women were subjected to GCT either at first visit or between 24-28 weeks on the basis of risk profile. High risk cases were screened at first visit and the rest between 24-28 weeks.

GCT was performed with 50 gram glucose challenge independent of the time and type of last meal and followed one hour later by estimation of plasma glucose, cut off value was taken as $>140 \mathrm{mg} / \mathrm{dl}$.

\section{Inclusion criteria for GCT}

1. All antenatal cases with the following risk factors were subjected to GCT at first ANC visit:

- Severe obesity i.e. BMI more than $35 \mathrm{~kg} / \mathrm{m}^{2}$;

- Family history of type -2 Diabetes mellitus in first degree relatives;

- Previous history of GDM;

- Age more than 35 years;

- Previous pregnancy resulting in a child with high birth weight $\left(>90^{\text {th }}\right.$ percentile on lubchencko growth curves or $>4 \mathrm{kgs}$ );

- Previous poor obstetric history (still birth, malformations in baby, early neonatal death, instrumental or difficult delivery).

2. Others screened between 24 and 28 weeks.

\section{Exclusion criteria for GCT}

1. Pre-gestational or diagnosed GDM before reporting to GTB hospital;

2. Patients on glucocorticoids or any hypoglycemic drugs; 
3. Patients with multiple gestation;

4. Period of gestation $>28$ weeks.

Patients with a GCT value $\geq 200 \mathrm{mg} / \mathrm{dl}$ were not subjected for GTT and were diagnosed as GDM.

Value of GCT $<140 \mathrm{mg} / \mathrm{dl}$ was taken as normal. Irrespective of GCT result, women were subjected to glucose tolerance test as recommended by $\mathrm{WHO}$ with 75-gram glucose using WHO criteria. The test was performed in the morning after overnight fast of at least 8 hours but not more than 14 hours and after at least 3 days of unrestricted diet $(\geq 150 \mathrm{gm}$. carbohydrate/day) and physical activity. After drawing one $\mathrm{ml}$ fasting venous blood sample, an oral $75 \mathrm{gm}$ glucose load was given as a plain glucose or lemon/orange flavoured drink if plain glucose not tolerated. Second venous blood sample was collected after 2 hours. Plasma glucose was estimated in both the samples by the standard GOD-POD (Glucose Oxidase Peroxidase) method.

The reports of both fasting and the $2 \mathrm{hr}$ OGTT reports were interpreted as indicated in Tables $1 \& 2$ respectively.

Table 1. Interpretation of fasting plasma glucose values

\begin{tabular}{|c|c|}
\hline $\begin{array}{l}\text { FASTING PLASMA GLUCOSE } \\
\mathrm{mg} / \mathrm{dl}\end{array}$ & CRITERIA \\
\hline$<100$ & Normal \\
\hline $100-125$ & Impaired fasting glucose (IFG) \\
\hline$\geq 126$ & Diabetes mellitus (DM) \\
\hline
\end{tabular}

Table 2.Interpretation of OGTT with 75 gms glucose (WHO criteria*)

\begin{tabular}{|l|l|}
\hline \multicolumn{1}{|c|}{ Plasma Glucose } & \multicolumn{1}{c|}{ In Pregnancy } \\
\hline $2 \mathrm{hr} \geq 200 \mathrm{mg} / \mathrm{dl}$ & Diabetes \\
\hline $2 \mathrm{hr} \geq 140 \mathrm{mg} / \mathrm{dl} \& \leq 199 \mathrm{mg} / \mathrm{dl}$ & GDM \\
\hline $2 \mathrm{hr} \geq 120 \mathrm{mg} / \mathrm{dl} \& \leq 139 \mathrm{mg} / \mathrm{dl}$ & $\begin{array}{l}\text { GGl(Gestational glucose } \\
\text { impairment) }\end{array}$ \\
\hline $2 \mathrm{hr}<120 \mathrm{mg} / \mathrm{dl}$ & Normal \\
\hline
\end{tabular}

A fasting glucose level of $>126 \mathrm{mg} \%$ and random plasma glucose level of more than $200 \mathrm{mg} \%$ meets the threshold for diagnosis of Diabetes and precludes the need of any glucose challenge test
Study group comprised of 4 categories of patients with abnormal glucose homoeostasis as defined by following criteria:

1. Abnormal GCT $(\geq 140 \mathrm{mg} / \mathrm{dl})$ with normal OGTT;

2. Normal GCT with only impaired fasting glucose (IFG) in OGTT;

3. Normal GCT with gestational glucose intolerance (GGI);

4. Patients diagnosed as GDM:

a. If fasting is $>126 \mathrm{mg} / \mathrm{dl}$;

b. If $2 \mathrm{hr}$ OGTT $\geq 140 \mathrm{mg} / \mathrm{dl} \& \leq 199 \mathrm{mg} / \mathrm{dl}$;

c. If value of either GCT or OGTT $\geq 200 \mathrm{mg} / \mathrm{dl}$.

The control group comprised of women with normal GCT and normal 0GTT.

In all the above groups, adverse prenatal outcome and maternal outcomes were evaluated by the primary and secondary outcome measures.

\section{Primary outcomes:}

- Birth weight more than $90^{\text {th }}$ percentile (Lubchencko growth curves) for gestational age or $>4 \mathrm{kgs}$ (macrosomia);

- Neonatal hypoglycemia (Venous blood glucose $<40$ $\mathrm{mg} / \mathrm{dl}$, irrespective of gestational age);

- Comparison of cord blood sugar and C-peptide levels between cases with GDM, IFG, GGI and controls.

\section{Secondary outcomes:}

- Premature delivery (before 37 weeks of gestation);

- Preeclampsia;

- Operative deliveries;

- Birth injury;

- Duration of stay in NICU;

- Hyperbilirubinemia (Based on gestational age acc to CDC charts);

- Hypocalcaemia (Serum calcium $<7 \mathrm{mg} / \mathrm{dl}$, Ionized calcium $<4 \mathrm{mg} / \mathrm{dl}$ );

- Polycythemia (symptomatic with $\mathrm{PCV} \geq 65$, asymptomatic with $\mathrm{PCV} \geq 70$ ).

\section{Statistical analysis}

Data was analyzed by using SPSS version (17) of statistical software. Study group and controls were compared by $\mathrm{T}$ test. Comparison between the various categories of study group for quantitative parameters was done by one way ANOVA. $P<0.05$ was considered significant. All values were expressed as mean \pm standard 
deviation. Various parameters were compared between the categories by chi square test for all categorical variables.

\section{OBSERVATIONS AND RESULTS}

In the present study, 340 antenatal women were recruited from Nov'11 to Nov'12. Out of 340, 18 women were not willing to participate. A total 322 women were screened by GCT and OGTT of which 22 women were excluded as 15 women did not report for OGTT after initial GCT testing and 7 were lost to follow up. Hence a total of 300 women were enrolled in the study.

Women belonging to high-risk category were screened at their first visit. Rest all women were screened from 24 to 28 weeks. Among high risk 6 were screened from 10 to 16 weeks, 4 from 18 to 22 weeks and 2 from 21 to 22 weeks of gestation. Among the high-risk groups, 6 had family history of diabetes in first degree relatives, 4 had GDM in previous pregnancy and 2 had previous poor pregnancy outcomes. (Table 3).

Abnormal glucose homeostasis was detected in 65 women who formed the study group (21.6\%). An equal number of patients $(\mathrm{n}=65)$ with normal glucose homeostasis were taken as controls. The patients profile in cases and control group was comparable.

The age distribution of patients in the study groups ranged from $19-32$ yrs with mean of $24.01 \pm 2.7$, which was comparable to the control group. The mean age, height, weight(pre-pregnancy), BMI (pre-pregnancy) and blood pressure at first visit were also comparable between the study and control groups (Table 4).

Table 3. Patient's profile in study and control groups

\begin{tabular}{|c|c|c|c|}
\hline Parameters & $\begin{array}{l}\text { Study group \% } \\
\qquad(n=65)\end{array}$ & $\begin{array}{l}\text { Controls } \% \\
\qquad(n=65)\end{array}$ & $P$ value \\
\hline $\begin{array}{l}\text { 1. High risk category } \\
\begin{array}{l}\text { - } \quad \text { Family history first degree relatives } \\
\text { - } \quad \text { GDM in previous pregnancy } \\
\text { - } \quad \text { Previous Poor pregnancy outcomes }\end{array}\end{array}$ & $\begin{array}{c}15.3(10) \\
(5) \\
(4) \\
(1)\end{array}$ & $\begin{array}{l}3(2) \\
(1) \\
(0) \\
(1)\end{array}$ & 0.030 \\
\hline Multi gravid & $44.6(29)$ & $35.4(23)$ & 0.220 \\
\hline Previous LSCS & $10.7(7)$ & $10.7(7)$ & 1 \\
\hline Family h/o First degree relative & $7.6(5)$ & $1.5(1)$ & 0.208 \\
\hline
\end{tabular}

Table 4. Demographic parameters

\begin{tabular}{|l|c|c|c|}
\hline Parameters & Study group & Control group & P value \\
\hline Age $($ Yrs $)$ & $24.01 \pm 2.7$ & $23.93 \pm 3.0$ & 0.634 \\
\hline Height $(\mathrm{cm})$ & $153 \pm 4.2$ & $152.6 \pm 4.0$ & 0.813 \\
\hline Pre-pregnancy weight $(\mathrm{kg})$ & $52.4 \pm 4.4$ & $49.7 \pm 3.5$ & 0.200 \\
\hline Pre-pregnancy BMl $\left(\mathrm{kg} / \mathrm{m}^{2)}\right.$ & $22.3 \pm 2.4$ & $21.3 \pm 1.9$ & 0.291 \\
\hline SBP $(\mathrm{mm} \mathrm{Hg})$ & $124 \pm 9.7$ & $117.4 \pm 7.3$ & 0.202 \\
\hline DBP $(\mathrm{mm} \mathrm{Hg})$ & $81.2 \pm 6.3$ & $74.7 \pm 6.0$ & 0.761 \\
\hline
\end{tabular}


The mean period of gestation at which GCT was performed among study group and control was $25 \pm$ 2.3 weeks and $25.4 \pm 1.9$ weeks respectively. The GCT, fasting glucose, and $2 \mathrm{hr}$ OGTT value in control group was in range from $61-124 \mathrm{mg} / \mathrm{dl}, 60-89 \mathrm{mg} / \mathrm{dl}$ and $78-$ $119 \mathrm{mg} / \mathrm{dl}$ respectively, while that in study group from $94-180 \mathrm{mg} / \mathrm{dl}, 68-140 \mathrm{mg} / \mathrm{dl}$ and $102-180 \mathrm{mg} / \mathrm{dl} \mathrm{re}-$ spectively (Table 5).

Table 5. The mean GCT, fasting, and $2 \mathrm{hr}$ value of OGTT among study and control group

\begin{tabular}{|l|c|c|}
\hline $\begin{array}{l}\text { Parameters } \\
\text { (Blood sugar) }\end{array}$ & $\begin{array}{c}\text { Study group } \\
(\mathbf{n}=65)\end{array}$ & $\begin{array}{c}\text { Control group } \\
(\mathbf{n}=65)\end{array}$ \\
\hline GCT $(\mathrm{mg} / \mathrm{dl})$ & $146.7 \pm 16.8$ & $91.3 \pm 14.3$ \\
\hline FASTING $(\mathrm{mg} / \mathrm{dl})$ & $90.7 \pm 13.0$ & $73.1 \pm 5.7$ \\
\hline 2 HOUR $(\mathrm{mg} / \mathrm{dl})$ & $137.2 \pm 18.4$ & $100.7 \pm 8.9$ \\
\hline
\end{tabular}

Among the study group $72.3 \%$ had abnormal GCT (47) and $27.6 \%$ had normal GCT with abnormal glucose homeostasis in the form of, IFG in 3 (16.6\%), GGI in $10(55.5 \%)$ and GDM in 5 cases $(27.7 \%)$. The sensitivity and specificity of GCT was $87.1 \%$ and $63.2 \%$ respectively (Table 6).

Table 6. The mean GCT, fasting, and $2 \mathrm{hr}$ value of OGTT among study and control group

\begin{tabular}{|l|c|c|c|}
\hline Parameters & Distribution & No of cases & $\begin{array}{c}\text { \% of study } \\
\text { group }\end{array}$ \\
\hline \multirow{2}{*}{ GCT $(\mathrm{mg} / \mathrm{dl})$} & Normal & 18 & 27.6 \\
\cline { 2 - 4 } & Abnormal & 47 & 72.3 \\
\hline \multirow{2}{*}{$\begin{array}{l}\text { FASTING GLUCOSE } \\
\text { (mg/dl) }\end{array}$} & Normal & 48 & 73.8 \\
\cline { 2 - 4 } & $\begin{array}{c}\text { Impaired } \\
\text { (IFG) }\end{array}$ & 17 & 26.2 \\
\hline \multirow{2}{*}{2 HR OGTT $(\mathrm{mg} / \mathrm{dl})$} & Normal & 17 & 26.2 \\
\cline { 2 - 4 } & GGI & 14 & 21.5 \\
\cline { 2 - 4 } & Abnormal & 34 & 52.3 \\
\hline
\end{tabular}

Among the study group 14 had only abnormal GCT (21.5\%), 3 had only IFG (4.6\%), 14 had only GGI (21.5\%), and 34 had GDM (52.3\%) constituting a prevalence of abnormal GCT, IFG, GGI and GDM in $4.6 \%, 1 \%, 4.6 \%$, and $11.3 \%$ of patients respectively among the 300 patients screened.
While 20 (59\%) cases of GDM were controlled on diet and exercise, in 14 (41\%) cases insulin was also required. No treatment was given for other 3 categories of abnormal glucose homoeostasis in the study group.

\section{Maternal and perinatal complications}

There were 10 cases (15.3\%) of hypertensive disorder of pregnancy in the study group (3 cases of gestational hypertension in abnormal GCT, 3 cases of pre eclampsia in each GGI and GDM and 1 antepartum eclampsia in GGI category) and 2 cases in control group (3\%) $(p=0.03)$. There were 2 cases of FGR and 5 cases of PROM in both study and control group. There was 1 case of cholestasis of pregnancy in study group.

Two intrauterine deaths (IUD) were noted in present study. One baby had gross congenital anomaly (spina bifida) at 33 weeks of gestation in GDM category and the other had unexplained IUD at term. Mild birth asphyxia (Apgar 6-7) was present in 13 and 8 cases of study group and controls respectively. There was one neonatal death in NICU at day-14 due to sepsis in view of preterm delivery.

\section{TERMINATION OF PREGNANCY}

Labour was induced in 13 patients in both study and control group. There were 4 cases of preterm labour $(2$ induced +2 spontaneous), both induced cases belonging to the GDM category. Term inductions were 11 and 13 in the study and control group respectively. Number of patients in either group was not statistically different Within the study group number of cases induced were more in GGI $(n=7)$ and GDM $(n=4)$ category. The reasons for induction in GGI group were PROM (3), decrease fetal movements (3) and cholestasis of pregnancy (1). In GDM group reasons were severe pre-eclampsia(1), antepartum eclampsia(1),PROM(2). There were 2 inductions in abnormal GCT group in view of FGR. The mode of induction was misoprostol for all except in FGR and antepartum eclampsia where $\mathrm{PGE}_{2}$ was given. The reasons for induction in control group were PROM (5), post dated (2), FGR (2), reduced fetal movement (4).

There were 14 ( 7 elective +7 emergency) caesarean sections $(21.5 \%)$ and $2(3 \%)$ instrumental deliveries (in view of fetal distress and prolonged $2^{\text {nd }}$ stage) among the study group. Reasons for elective LSCS were GDM 
with breech (1), GDM with fetal weight estimated to be $>4000 \mathrm{~g}(3)$, GDM with previous LSCS (1), abnormal GCT with breech(1), IFG with prev LSCS short inter pregnancy interval (1). However, there were 6 caesarean (1 elective+5 emergency) sections (9.2\%) and no instrumental deliveries among control groups (Table 7). However, number of primary cesarean was comparable between the study group and controls.

Table 7. Mode of termination of pregnancy

\begin{tabular}{|l|c|c|c|}
\hline \multicolumn{1}{|c|}{ Parameters } & $\begin{array}{c}\text { Study group } \\
(\mathbf{n = 6 5 )}\end{array}$ & $\begin{array}{c}\text { Controls } \\
(\mathbf{n = 6 5 )}\end{array}$ & P value \\
\hline Pre term induction & 2 & 0 & 0.49 \\
\hline $\begin{array}{l}\text { Pre term spontane- } \\
\text { ous labour }\end{array}$ & 0 & 2 & 0.49 \\
\hline Term inductions & 11 & 13 & 0.82 \\
\hline $\begin{array}{l}\text { Term spontaneous } \\
\text { labour }\end{array}$ & 38 & 44 & 0.36 \\
\hline Elective LSCS & 7 & 1 & 0.05 \\
\hline Emergency LSCS & 7 & 5 & 0.76 \\
\hline
\end{tabular}

The rate of elective LSCS was more in GDM ( $\mathrm{n}=5)$ vs other 3 categories and the difference was significant $(p=0.04)$. The over all number of LSCS (14 cases) was significantly higher in GDM $(n=9)$ and the risk increased among the 4 categories $(\mathrm{p}=0.003)$.

There were 2 post-dated pregnancies in the control group, while no post-dated pregnancy was noted in the study group. The mean period of gestation at delivery in the study group was in range from 33-41 weeks, with a mean of $38.1 \pm 1.3$ weeks and in control group was in range from $35-41$ weeks with a mean of $39.3 \pm 1.07$ weeks $(p=0.266)$. Duration of labour in the study group for primi and multigravida was comparable.

\section{DISCUSSION}

In the present study, 300 antenatal women were screened for abnormal glucose homeostasis by GCT followed by OGTT between 24 to 28 weeks of gestation or earlier depending on the patients risk profile. Among all screened abnormal glucose homeostasis were detected in 65 women in the form of abnormal GCT, IFG, GGI, and GDM, constituting a prevalence of $21.6 \%$ and form the study group. Equal numbers of controls were also selected from those 300 patients. Perinatal outcome was evaluated among study groups with impaired glucose homeostasis, with that of controls.

Among total screened 47 women were diagnosed as abnormal GCT comprising the prevalence to be $15.6 \%$. The study group 14 were of only abnormal GCT, 3 with IFG, 14 with GGI, and 34 were of GDM category constituting $4.6 \%, 1 \%, 4.6 \%$, and $11.3 \%$ of prevalence of only abnormal GCT, IFG, GGI and GDM respectively among total screened. The prevalence of GDM was $11.3 \%$ in present study and that reported by $\mathrm{ADA}$ (in American population), and IADPSG (globally) is $7 \%$ and $17.8 \%$ respectively ${ }^{7,8}$. According to DIPSI the prevalence of GDM in India varies from 3.8 to $21 \%$ in different parts of country, depending on geographical locations ${ }^{9}$.

In present study even with normal GCT 27.6\% cases exhibited some form of abnormal glucose homeostasis in form of IFG, GGI, and GDM detected in 3,10 and 5 cases respectively. Normally GTT is not done in women with normal GCT. Since in present study GTT was performed in all cases irrespective of GCT, it was found that GCT lacks specificity (63.2\%). Seshiah et al found that $21.5 \%$ of GDM cases were left undiagnosed by initial GCT screening and they found the specificity of $41.8 \%{ }^{10}$.

In the present study hypertensive disorders of pregnancy were observed fivefold higher in study group (15.3\%)than in controls(3\%) ( $\mathrm{p}=0.03)$. Among study group, gestational hypertension and pre-eclampsia was not confined to GDM category (40\%) but was also observed in abnormal GCT(30\%) and GGI (30\%) categories. A case of antepartum eclampsia had occurred in GGI category at 33 weeks period of gestation, who was a defaulter to follow up after enrolment in the study. Jang et al reported that the frequency of pre-eclampsia was eight-fold higher in GDM (10.8\%) cases compared to patients with normal glucose tolerance $(1.3 \%)^{11}$. Another study by Landon et al also found that pre-eclampsia or gestational hypertension was significantly more in GDM group (15\%) compared to abnormal GCT (8\%), IGT and controls ${ }^{12}$.

In present study there were 2 preterm inductions in study group (3\%) and 2 preterm spontaneous labour in control group (3\%). This result was similar to that reported by Jang et al as no significant difference was there in preterm deliveries between $\operatorname{GDM}(6.2 \%)$ and 
NGT(2.6\%)group ${ }^{11}$. While Yang et al reported significant difference of preterm deliveries between NGT (1.32\%) and IGT $(7.8 \%)^{5}$.

There were 14 ( 7 elective +7 emergency) caesarean sections (21.5\%) and $2(3 \%)$ instrumental deliveries among study groups. However, there were 6 caesarean (1 elective +5 emergency) sections (9.2\%) and no instrumental deliveries among control groups $(\mathrm{P}=0.04)$. The number of primary caesarean was comparable between study group and controls. The incidence of LSCS in GDM, GGI and abnormal GCT category was $26.3 \%$, $21.4 \%$ and $7.1 \%$ respectively. Jang et al reported that overall rate of caesarean section was not different between the GDM (55.4\%) and NGT (45.1\%); however, the rate of primary caesarean section was significantly higher in those with GDM (40\%) vs NGT $(22.9 \%)^{11}$. In HAPO study also it was observed that when the glucose measures were analysed as continuous variables, fasting and $2 \mathrm{hr}$ both were significant predictors of primary caesarean delivery, with 1-SD increases in glucose level being associated with an increase of 8 to $11 \%$ in the odds of delivery by caesarean section ${ }^{13}$. The results of present study were comparable to that of above 2 studies.

In present study the mean birth weight among study group $(3.03 \pm .53 \mathrm{~kg})$ was significantly higher than in control groups. There were 12 cases of macrosomia (18.4\%) with mean birth weight of $3.6 \pm 0.49 \mathrm{~kg}$ among study group. Macrosomia was present in GDM category $(n=11)$ followed by IFG $(n=1)$ and none in GGI and abnormal GCT however the difference of mean birth weight was not significant.

Khoshniat et al reported prevalence of macrosomia in $15.8 \%, 6 \%, 3.6 \%$ and $1.1 \%$, patients with GDM, IGT, only abnormal GCT and normal GCT respectively; and in contrast to present study the differences between the groups were significant ${ }^{14}$.

In present study difference among cord blood sugar levels at birth among babies of Controls and study group was not statistically significant. Similar non-significant result for hypoglycaemia was observed by Yang et al as there was $0.33 \%$ hypoglycaemia in NGT group vs $0.98 \%$ in IGT $^{5}$.

The value of cord blood C-peptide in present study was significantly different between study $(2.5 \pm 0.85 \mathrm{ng} /$ $\mathrm{ml})$ and Control groups (1.51 $\pm .43 \mathrm{ng} / \mathrm{ml})$. Among study group significantly higher $\mathrm{C}$-peptide levels were observed in GDM group followed by abnormal GCT and GGI. $90^{\text {th }}$ percentile $(3.12 \mathrm{ng} / \mathrm{ml})$ of C-peptide was also calculated from study groups and controls, and it was observed that $>90^{\text {th }}$ percentile C-peptide was observed in GDM category only (18.4\%). Dube et al reported Cord blood C-peptide from newborns of GDM women tended to be significantly higher than those from NGT women supporting results of present study ${ }^{15}$.

In present study hyperbilirubinemia was higher in study group (17.4\%) than in controls and more than half belonging to GDM category. However, the difference between study group and controls was not significant. There was NICU stay of more than 7 days in 11 cases of study group, of which 5 (45.4\%) were of GDM category.

The incidence for NICU admission was $4.9 \%$ in GDM group according to study by Al-hakeem ${ }^{16}$. The commonest cause for NICU admission was hyperbilirubinemia (41.2\%) among all cases of GDM. Ostlund et al reported admission to NICU for 2 days or longer was more common (adjusted OR 2.0, 95\% CI 1.1-3.8) in IGT than controls. ${ }^{17} 71.3 \%$ of the children in the IGT group and $87.3 \%$ of the control subjects had no neonatal complications.

\section{CONCLUSIONS}

1. Abnormal GCT was detected in $15.6 \%$ of pregnant women (47/300) and this group accounted for $72.3 \%$ Cases (47/65) of any form of abnormal glucose homeostasis.

2. Even women with normal GCT had disturbed glycemic status like IFG, GGI, or GDM.

3. Specificity of GCT to diagnose GDM was only $63.2 \%$.

4. Cases with abnormal glucose homeostasis of lesser degree than GDM, like only abnormal GCT, IFG and GGI also were observed to have adverse maternal outcomes than controls, in form of hypertensive disorders of pregnancy, significantly higher LSCS rates, and increased risk of macrosomia.

5. Instead of 2 step procedure, single step screening cum diagnostic test with $75 \mathrm{gm}$ OGTT for diagnosing GDM would be an option to be universally practiced.

6 . Besides fasting and $2 \mathrm{hr}$ value importance should also be given to GGI category ( $2 \mathrm{hr}$ value between 120 $139 \mathrm{mg} / \mathrm{dl}$ ) as suggested by DIPSI modification of WHO criteria.

7. Whether women with IFG and GGI would benefit with dietary modification would be clear by evaluating large number of studies in multicentric design. 
Compliance with ethics requirements: The authors declare no conflict of interest regarding this article. The authors declare that all the procedures and experiments of this study respect the ethical standards in the Helsinki Declaration of 1975, as revised in 2008(5), as well as the national law. Informed consent was obtained from all the patients included in the study.

\section{References}

1. American Diabetes Association. Diagnosis and classification of diabetes mellitus (Position Statement). Diabetes Care 2009;32 (Suppl.1):S62-7.

2. Metzger BE, Coustan DR. Summary and recommendations of the Fourth International Workshop-Conference on Gestational Diabetes Mellitus: the organizing committee. Diabetes Care 1998;21(Suppl. 2):B161-67.

3. O'sullivan JB, Mahan CM. Criteria for oral glucose tolerance test in pregnancy. Diabetes 1964;13:278-85

4. Cutchie WA, Cheung NW, Simmons D. Comparison of international and New Zealand guidelines for the care of pregnant women with diabetes. Diabet Med 2006;23:460-8.

5. Yang $X$, Hsu-Hage B, Zhang H, Zhang C, Zhang Y, Zhang C. Women with impaired glucose tolerance during pregnancy have significantly poor pregnancy outcomes. Diabetes Care 2002;25:1619-24.

6. Ferrara A, Weiss NS, Hedderson MM, Quesenberry CP Jr, Selby $J V$, Ergas IJ, et al. Pregnancy plasma glucose levels exceeding the American Diabetes Association thresholds, but below the National Diabetes Data Group thresholds for gestational diabetes mellitus, are related to the risk of neonatal macrosomia, hypoglycaemia and hyperbilirubinaemia. Diabetologia 2007;50:298-306.

7. American Diabetes Association. Standards of medical care in diabetes - 2010. Diabetes Care 2010; 33: S11-S61.

8. International association of diabetes and pregnancy study groups recommendations on the diagnosis and classification of hyperglycemia in pregnancy. Diabetes Care 2010; 33: 676-82.

9. Seshiah V, Balaji V, Balaji MS, Sekar A, Sanjeevi CB, Green A. One step procedure for screening and diagnosis of gestational diabetes mellitus. J Obstet Gynecol 2005;55(6):525-9.

10. IDF Clinical Guidelines Task Force. Global Guideline on Pregnancy and Diabetes. Brussels: International Diabetes Federation, 2009. Available from: http://www.idf.org/webdata/docs/Pregnancy_EN_RTP.pdf. Accessed on: 12th Dec., 2012
11. Jang $\mathrm{HC}$, Cho NH, Min YK, Han IK, Jung KB, Metzger BE. Increased macrosomia and perinatal morbidity independent of maternal obesity and advanced age in Korean women with GDM. Diabetes Care 1997;20(10):1582-8.

12. Landon MB, Mele L, Spong CY, Carpenter MW, Ramin SM, Casey $B$, et al. The relationship between maternal glycemia and perinatal outcome. Obstet Gynecol 2011;117(2 Pt 1):218-24.

13. Metzger BE, Lowe LP, Dyer AR, Trimble ER, Chaovarindr U, Coustan DR, et al. Hyperglycemia and adverse pregnancy outcomes. N Engl J Med 2008; 358: 1991-2002.

14. Khoshniat nikoo M, Garshasbi A, Amini S, Pasandi F, Peimani M, Larijani B. Relationship between maternal glucose intolerance and fasting plasma glucose with macrosomia during pregnancy. Iranian Journal of Diabetes and Lipid Disorders; 2010; Vol 9, pp $1-7$

15. Dubé MC, Morisset AS, Tchernof A, Weisnagel SJ. Cord blood C-peptide levels relate to the metabolic profile of women with and without gestational diabetes. Acta Obstet Gynecol Scand 2012;91(12):1469-73.

16. Al-Hakeem MM. Pregnancy outcome of gestational diabetes mothers: experience in a tertiary centre. J Fam Commun Med 2006;13(2).

17. Ostlund I, Hanson U, Björklund A, Hjertberg R, Eva N, Nordlander E et al.. Maternal and fetal outcomes if gestational impaired glucose tolerance is not treated. Diabetes Care 2003;26(7):2107-11. 